\title{
Envelhecer nas perspectivas sobre tempo, experiência e consciência de classe em Edward Palmer Thompson e Antônio Gramsci
}

\author{
Elaine Lima Silva*, Juceli Aparecida Silva**
}

\section{Resumo}

O artigo trata sobre as questões do enveIhecimento humano sob a perspectiva dos conceitos de "tempo", "consciência de classe" e "experiência" em Edward Palmer Thompson e Antônio Gramsci, em diálogo com outros autores. A partir da revisão narrativa da literatura, concluiu-se que o envelhecimento não pode ser definido como algo homogêneo, linear ou reduzido a certo "economismo". Com base nas particularidades e sutilezas dos costumes dos povos durante o processo de industrialização na Inglaterra no século XVIII e no movimento dos aposentados no Brasil na década de 1990, pode-se observar como o conceito de envelhecimento e o lugar das pessoas idosas e/ou aposentadas foram gradativamente se alterando e modificando a partir de mudanças nas concepções de tempo, experiência e consciência de classe.

Palavras-chave: Consciência de classe. Envelhecimento. Experiência. Tempo.

\section{Introdução}

Este artigo se propõe refletir questões a respeito do envelhecimento humano sob a perspectiva de Edward Palmer Thompson (1985, 1998) em diálogo com alguns autores, especialmente Antônio Gramsci (2000), Stuart Hall (2003a) e Ecléa Bosi (2003), a respeito dos conceitos de "tempo", "experiência" e "consciência de classe". Sabe-se que Thompson, Gramsci e Hall não se dedicaram ao estudo das velhices, porém, justificamos a escolha por esta base teórica, ora por considerarmos que categorias como velhice e envelhecimento estão atreladas aos modos de produção das sociedades, influenciando na forma como homens e mulheres envelhecem; ora porque a questão do aumento da expectativa de

* Mestre em Sociologia (Programa de Pós-Graduação em Sociologia Política, Universidade Federal de Santa Catarina). Endereço para correspondência: Rua Deputado Antônio Edu Vieira, 147, 402-C, Bairro Pantanal, 88040-000, Florianópolis, SC. E-mail: elainehumanas@gmail.com

* Psicóloga (Universidade Regional de Blumenau). Mestre em Sociologia Política (Programa de Pós-Graduação em Sociologia Política, Universidade Federal de Santa Catarina). E-mail: juceli_s@hotmail.com

$\rightarrow$ http://dx.doi.org/10.5335/rbceh.v14i2.6092

Recebido em: 03.06.2016. Aceito em: 08.08.2017. 
vida não é um fato estático, nem localizado, mas que se alterna em diferentes períodos históricos.

De acordo com Thompson (1998), o passado humano não é um agregado de histórias separadas, mas uma soma unitária do comportamento humano, em que cada aspecto se relaciona com outros de determinadas maneiras. Em Costumes em comum (1998), Thompson procura refletir sobre o tempo entre grupos de camponeses e pequenos agricultores, fazendo menção às comunidades ditas primitivas, mas direciona seu foco para a noção de tempo a partir das transformações ocorridas com o advento da Revolução Industrial inglesa. $\mathrm{O}$ autor relaciona as mudanças nas formas de medir o tempo com as transformações no sistema de produção. Nesse ínterim, inserimos o debate de como as velhices foram subjugadas às categorias criadas nesse âmbito.

Para que os objetivos desta pesquisa fossem alcançados, a sua fundamentação teórico-metodológica foi desenvolvida por meio da revisão narrativa dos autores e dos respectivos conceitos utilizados, especialmente em E. P. Thompson (1985, 1998), Antônio Gramsci (2000), Stuart Hall (2003a) e Ecléa Bosi (2003). Nossa intenção não foi esgotar as fontes de informações sobre os conceitos apresentados, mas responder adequadamente aos objetivos propostos. O artigo está dividido em três etapas. Inicia-se com uma breve contextualização sobre E. P. Thompson; num segundo momento, expõem-se alguns conceitos sobre envelhecimento e a forma como seu processo foi sendo moldado pelas mudanças nas conotações de "tempo"; e, por último, coteja-se a questão da aposentadoria com o conceito de "consciência de classe" em Gramsci, levando o(a) leitor(a) a refletir sobre como homens e mulheres - jovens ou velhos - vivenciam seu tempo e como experiências coletivas podem determinar suas velhices e propiciar uma ampliação de sua participação política, enquanto sujeitos históricos em transformação e transformadores das realidades sociais.

\section{Pensamento de E. P. Thompson}

No Brasil, existem poucas obras traduzidas de E. P. Thompson, apesar disso, seus estudos e obras foram amplamente difundidos entre os estudiosos da sociologia e da antropologia entre os anos de 1986 e 1998 (BADARÓ MATTOS, 2012). Segundo Müller, Thompson foi "um dos autores mais influente, polêmico e citado nas ciências sociais" (MÜLLER, 2012, p. 305). Significativa parte de sua contribuição se deu por meio de estudos sobre a formação da classe operária inglesa (THOMPSON, 1998). Para Müller (2012), ele reafirmava a importância dos princípios metodológicos, o diálogo entre teoria e empiria em qualquer pesquisa, e procurava estabelecer uma abordagem crítica do cenário político intelectual contemporâneo, inserindo os valores comunitários da classe trabalhadora.

Thompson reviu criticamente o conceito de classe e propôs uma dialética particular entre a experiência e a consciência. Destacava a historicidade das categorias enquanto valorizava 
a importância das práticas (práxis) (MÜLLER, 2012). Questionou a ideia de que os homens são produtos somente concebidos por forças materiais, procurou recuperar em Marx a tese de que o povo se educa em sua própria práxis, como sujeito da história. Os estudos de Thompson valorizam a importância da práxis envolvendo prática, experiência, aspirações e valores (comunitários, religiosos, entre outros) da classe trabalhadora (MÜLLER, 2012).

Thompson baseou seu trabalho na relação entre o agir humano (agency) e a atuação política consciente e coerente. Analisar os sujeitos implicados na construção de seus próprios destinos era o foco principal de seus estudos. Thompson tinha um compromisso com o movimento histórico, no qual história e teoria socialista deveriam participar do processo de democratização. Militou e participou de movimentos pacifistas, na organização de documentos, ensaios e livros (THOMPSON, 1985). Foi membro do Partido Comunista da Grã-Bretanha entre os anos de 1942 e 1956; após o rompimento com o partido, tornou-se defensor de uma concepção humanista de socialismo (contra o stalinismo). Desempenhou um papel central na formação de uma Nova Esquerda, discutida por intermédio do Manifesto de $1^{\circ}$ de Maio de 1968 (WILLIAMS et al., 1968).

Stuart Hall (2003b) relembra que, na década de 1950, a Inglaterra fornecia um contexto singular para reflexão acadêmica. Ao mesmo tempo, ele e outros colegas preferiram fundar a chamada Sociedade Socialista a se filiar ao partido comunista, pois, em suas palavras: "o marxismo nos interessava, mas não éramos dogmáticos; éramos antistanilistas e não defensores da União Soviética [...]" (HALL, 2003b, p. 419). Thompson fazia nascer a primeira Nova Esquerda britânica, a New Left, que envolveu outros grandes acadêmicos, como o historiador inglês Perry Anderson (1938-), o crítico e novelista galês Raymond Willians (19211988) e o sociólogo britânico Richard Hoggart (1918-2014). Esses trabalhos resultaram em significativa interação com os estudos de Antônio Gramsci (1891-1937) e de Louis Althusser (19181990), haja vista que ambos, intelectuais marxistas, propuseram novas perspectivas de reflexão dos processos políticos e sociais de dominação (LACLAU, 2014).

Thompson pretendeu resgatar uma tradição do marxismo na qual o modo de vida das pessoas pudesse ser mais bem considerado. Ele não negou a importância dos fatores materiais, entretanto, não acreditou que se pudesse estabelecer uma relação hierárquica: uma infraestrutura econômica que determinaria todas as outras.

Nessa lógica, Thompson dialoga com Hall (2003), afirmando, a partir de Gramsci, que não se pode atribuir a uma ordem social certo tipo de "economismo" ou "reducionismo" que se reduziriam a determinantes econômicos:

Economismo não significa ignorar a poderosa função que as fundações econômicas de uma ordem social ou as relações econômicas dominantes de uma sociedade exercem na forma e estruturação de todo o edifício da vida social. Mas, uma abordagem teórica 
específica que tenda a ler as fundações econômicas da sociedade como a única estrutura determinante $[. .$.$] nesse sentido o "eco-$ nomismo" é um reducionismo teórico. Ele simplifica a estrutura das formações sociais, reduzindo sua complexidade de articulação vertical e horizontal a uma única linha de determinação. Nivela todas as mediações entre os diferentes níveis de uma sociedade (2003a, p. 303-304).

Na direção da proposta de reflexão deste artigo, consideramos também que o aumento da expectativa de vida atende a inúmeras causas e relações de força e que não se podem reduzir as análises do envelhecimento a determinantes econômicos.

\section{As velhices e o tempo}

Simone de Beauvoir (1991) descreve como os chineses, os judeus e os gregos tratavam seus velhos. Na China, Confúcio justificava moralmente a autoridade, associando a velhice à posse da sabedoria; a longevidade para os judeus era considerada como "suprema recompensa da virtude"; as palavras gregas Géra e géron significam ao mesmo tempo idade avançada e o privilégio da ancianidade, a honra ligada à velhice, virtude imprescindível para o conselho de anciãos ligado ao rei na antiga Pólis (BEAUVOIR, 1991, p. 120). Cícero (2001) argumenta a respeito da vida ativa, indagando se a velhice é motivo de afastamento dos assuntos públicos, ao que ironicamente responde que um homem jovem e vigoroso não pode enfrentar sozinho, devendo valer-se da sabedoria dos mais velhos.
No ritual dos Kĩsêdjê ou Suyá, índios que habitam o Xingu do Mato Grosso no Brasil, os jovens iniciados são considerados como expressão máxima da ideia de masculinidade e autocontrole, enquanto o comportamento dos idosos é o oposto, caracterizado por humor, descontração e obscenidade. Os velhos da sociedade Kĩsêdjê têm o papel social de atuar como palhaços nos rituais, responsáveis por eventuais cenas de humor ao final da tarde, quando provocam risadas nos mais jovens. Também, a autoridade dos especialistas em rituais dos Suyá vem da sabedoria e da memória para cantos (SEEGER, 2003).

No ritual dos Kĩsêdjê ou Suyá, índios que habitam o Xingu do Mato Grosso no Brasil, os jovens iniciados são considerados como expressão máxima da ideia de masculinidade e autocontrole, enquanto o comportamento dos idosos é o oposto, caracterizado por humor, descontração e obscenidade. Os velhos da sociedade Kĩsêdjê têm o papel social de atuar como palhaços nos rituais, responsáveis por eventuais cenas de humor ao final da tarde, quando provocam risadas nos mais jovens. Também, a autoridade dos especialistas em rituais dos Suyá vem da sabedoria e da memória para cantos (SEEGER, 2003).

Magalhães (1989) considera que a homogeneidade nunca foi característica da velhice, velhos e velhas sempre foram venerados(as) ou denegridos(as) ao longo da história em sociedades distintas. Assim, também, a própria concepção de tempo - que redefine e ressignifica a concepção de envelhecimento - não é ho- 
mogênea, nem está atrelada a um modo linear na história dos povos. Thompson (1998) demonstra que, para os "povos primitivos", o tempo era medido a partir dos acontecimentos rotineiros, como os acontecimentos familiares no processo de trabalho. ${ }^{1}$ Porém, ainda conforme Thompson (1998), a notação de tempo a partir das tarefas se torna um problema quando se emprega "mão de obra", pois a economia familiar do pequeno agricultor pode ser orientada pelas tarefas, mas em seu interior pode haver divisão de trabalho, nesse caso, o tempo começa a se transformar em dinheiro, dinheiro do empregador, e o trabalho passa a se constituir por tarefas com horário marcado, redefinindo assim o próprio ciclo de vida do trabalhador.

De acordo com Thompson (1998), entre os povos das sociedades pré-industriais, a medição do tempo estava mais relacionada ao ciclo do trabalho rural (tempo de plantio e de colheita), à sucessão de tarefas domésticas e também aos hábitos, tempo de uma oração, por exemplo, em que os mais velhos detinham um lugar privilegiado, em que não havia divisão entre "trabalho" e "vida".

Tal concepção do tempo medido e vinculado ao trabalho na história linear ocidental pode ser vislumbrada por meio de um projeto de modernidade, iniciado, segundo Wallerstein $(2004,2006)$, no século XVI com as grandes navegações e reificado com as mudanças nos modos de produção na Inglaterra e com o Iluminismo, em que o ciclo da vida humana e, consequentemente, o envelhecimento foram universalizados no mundo oci- dental. O homem - antes, diluído numa ideia de um coletivo, dentro de uma dada comunidade - é tido como um indivíduo único, um adulto dotado de direitos e deveres, um trabalhador ativo. Embora as sociedades pré-industriais e sociedades não ocidentais tivessem algum tipo de marcação etária como critério de diferença, é na modernidade ${ }^{2}$ que se dá relevância à institucionalização do curso da vida, universalizando e regulamentando as sequências etárias, fazendo com que projetos e anseios individuais e coletivos fossem também definidos por esta institucionalização e pelo sistema capitalista.

Thompson (1998) tece críticas à coerência disciplinar na história, considerando que o conhecimento histórico é provisório, incompleto, seletivo e limitado. Ecléa Bosi, de certa forma, concorda com Thompson quando afirma: "Existe, dentro da história cronológica, outra história mais densa de substância memorativa no fluxo do tempo" (2003, p. 15). Bosi também constata que "[...] a história, que se apóia unicamente em documentos oficiais, não pode dar conta das paixões individuais que se escondem atrás dos episódios" (2003, p. 15). Para a autora, faz-se necessário ouvir as camadas que foram excluídas da história ensinada no ensino escolar, são eles e elas: "as mulheres", "os negros", "os trabalhadores manuais" e, evidentemente, "as pessoas velhas".

Bosi parece recuperar uma "história vista de baixo" no sentido de Thompson (1998), pois este dedicou seus estudos especialmente a partir das transfor- 
mações ocorridas não só entre as elites dirigentes, mas também entre grupos de operários e suburbanos, guardas das fábricas industriais e o trabalhador rural das sociedades pré-industriais.

Thompson (1998) nos ajuda a refletir sobre a influência das mudanças na concepção de tempo e de trabalho, expondo traços característicos da "cultura plebeia" no século XVIII, ao evidenciar que "o aprendizado, como iniciação em habilitações dos adultos, não se restringia à sua expressão formal na manufatura, mas também servia como mecanismo de transmissão entre gerações" (THOMPSON, 1998, p. 17-18). Assim, ele constatou que a criança aprendia suas tarefas caseiras primeiramente com sua mãe ou sua avó. Da mesma forma, as mães mais jovens aprendiam com matronas da comunidade como exercer seu papel de mãe. Assim como esses saberes particulares são transmitidos, também são transmitidos os saberes comuns da coletividade.

O aprendizado repassado na cultura plebeia apontado por Thompson demonstra o lugar social ocupado pelos mais velhos, o de transmissão do saber, mas também de resistência ao domínio ideológico dos governantes, de que não se trata apenas de uma "cultura tradicional", em que as normas não eram as mesmas proclamadas pela igreja ou pelas autoridades, eram definidas dentro da própria cultura plebeia. A transmissão de saber dos mais velhos é percebida por Bosi quando atesta que
[...] a memória dos velhos pode ser trabalhada como um mediador entre a nossa geração e as testemunhas do passado. Ela é o intermediário informal da cultura, visto que existem mediadores formalizados constituídos (escola, igreja, partido político, etc.) (2003, p. 15).

Para Ecléa Bosi (2003, p. 18), é pela memória oral que se inserem outras formas de observação dos fenômenos. Ela é o que a autora considera como uma "memória coletiva", que se desenvolve dentro de uma classe e que pode ser difundida, alimentando imagens, sentimentos, ideias e valores que constituem a identidade da classe em questão.

Privilegiar essa memória produzida no interior de uma classe é, no sentido de Thompson (1998), privilegiar outros elementos anteriores à própria formação de classe, elementos esses não incorporados à análise, como os costumes e os mitos. Podemos citar como um desses costumes, na Inglaterra do século XVIII, a lex loci, costumes do domínio senhorial, que, uma vez codificados, podiam ter a força da lei, mesmo estando registrados somente na memória dos idosos.

Thompson recupera experiências sociais anteriores ao surgimento do movimento de classe propriamente dito, atestando que, no período da Revolução Industrial, havia uma expressão de consciência que mais tarde seria objetivada como classe (VENDRAMINI, 2012). E, nessas experiências, a memória oral dos mais velhos tem lugar privilegiado, pois é a responsável pelo repasse desses costumes e mitos. 
Para Thompson, a expressão "luta de classes" conota que a luta (a experiência) é que deu origem à classe. De acordo com Andrade (2009), a classe social, para Thompson, não pode ser isoladamente definida pelo lugar dos indivíduos nas relações de produção, mas também a partir do acesso que têm a determinadas experiências, um termo chave no pensamento do autor. As experiências não podem ser compreendidas apenas como aquisição de comportamentos impostos, mas também como subjetivação, (re)significação, resistência, quando um grupo de indivíduos compartilha um conjunto de posicionamentos contrários a determinado vetor de poder (ANDRADE, 2009).

Um grupo de indivíduos que compartilha determinadas experiências pode ser percebido, pelo ponto de vista de Mannheim (1998), como uma "unidade geracional", ou seja, gerações que trabalham conjuntamente suas experiências. Essas unidades podem se constituir em forma de grupos, movimentos, associações, desde que se identifiquem em uma experiência comum.

Os aposentados podem servir como exemplo dessa unidade geracional, vinculados não só a movimentos, grupos, associações, como também à própria condição de pertencerem à categoria "terceira idade". Magalhães (1989) sugere terceira idade como um termo associado ao período de formação, atividade produtiva e inatividade remunerada, respectivamente atribuído a crianças e jovens, adultos e velhos aposentados. Segundo o autor, "[...] o conceito idoso envolve múltiplas dimensões, como a biológica, cronológica, social, demográfica, econômica, cultural, psicológica, ideológica e política" (MAGALHÃES, 1989, p. 15). Todas essas dimensões são ao mesmo tempo indissociáveis e dependentes umas das outras.

\section{Consciência de classe}

Gramsci (2000) faz a distinção entre a "classe em si" e a "classe por si", enquanto diferentes estágios em que a consciência, a organização e a unidade de classe - sob determinadas condições - podem se desenvolver. Primeiramente, o estágio do "corporativismo econômico", em que grupos reconhecem seus interesses básicos comuns, mas não têm consciência das solidariedades de classe mais ampla. Num segundo momento, o estágio do "corporativismo de classe", em que a solidariedade de interesses de classe se desenvolve, mas somente no campo econômico. E o estágio da "hegemonia", que transcende o limite corporativo da solidariedade econômica pura, engloba os interesses de outros grupos subordinados e começa a se propagar pela sociedade, promovendo a unidade intelectual, moral, econômica e política, propondo também as questões em torno das quais as lutas acontecem (GRAMSCI, 2000; HALL, 2003a).

A partir dessa distinção entre a "classe em si" e a "classe por si", propomos a reflexão a respeito do surgimento de uma "consciência de classe" e/ou de uma "classe por si mesma" no cenário brasileiro, por meio do seguinte exemplo de Barros: 
Entre 1991 e 1992 ocorreu "a mobilização pelos 147\%”, movimento de aposentados e pensionistas contra o projeto de reforma da Previdência Social do governo da época. Segundo Simões (2007), desde a década de 80 do século XX, manifestações ganharam notoriedade em suas "lutas hegemônicas", agindo de forma decisiva para fazer com que as discussões acerca da Previdência Social saíssem do âmbito técnico e acadêmico para ocupar posição central no debate político do país. Como bem demonstra o autor, uma categoria aparentemente 'marginal' e circunscrita ao domínio das relações privadas tornar-se uma espécie de 'corporação', com interesses específicos, demandas próprias e formas de atuação no espaço público [...] um movimento unitário de aposentados (BARROS, 2007, p. 14-15, grifo do autor).

Este é um evidente exemplo da influência do ser social sobre a consciência social ou do estágio da hegemonia considerado por Gramsci, que vai além do "limite corporativo da solidariedade econômica pura", para adentrar na luta, quando experiências comuns se articularam em prol de uma identidade: a do movimento de aposentados e pensionistas, a partir de interesses comuns contra outros que os diferiam. A mobilização pelos $147 \%$ pode ser vista, nesta análise, enquanto um estágio de hegemonia que se propagou pela sociedade, ampliando a luta não só para os aposentados, mas também para os pensionistas, legitimando sua "organização com base na condição de 'abandono' a que se acreditavam relegados pelos políticos e sindicatos" (BARROS, 2007, p. 14).

O exemplo citado pode ser percebido ainda do ponto de vista da concepção de classe social formulado por Thompson, que a considera como um fenômeno histórico não estático, algo que ocorre efetivamente nas relações humanas, não de uma forma determinada, mas como uma capacidade de percepção e articulação de interesses de alguns indivíduos contra outros, cujos interesses diferem dos seus. Thompson compreende ainda que:

A classe e a consciência de classe vão formando-se juntas na experiência [...] a consciência de uma identidade de interesses entre todos esses diversos grupos de trabalhadores, contra os interesses de outras classes. E, em segundo lugar, no crescimento das formas correspondentes de organização política e industrial (1998, p. 130).

É por intermédio da experiência que os homens (e as mulheres) experimentam situações e relações produtivas como necessidades e interesses, tratando dessa experiência em sua consciência e em sua cultura, não apenas a introjetando. A classe é definida enquanto os sujeitos vivem em sua própria história. Vendramini acrescenta que "a experiência surge espontaneamente no ser social, mas não surge sem pensamento. Surge porque homens e mulheres (e não apenas filósofos) são racionais e refletem sobre o que acontece a eles e ao seu mundo" (2012, p. 133).

No exemplo dado, de acordo com Barros (2007), a identidade política presente no discurso dos aposentados era a expressão: "somos a maior categoria do país". O movimento não surgiu por acaso, mas a partir das experiências de outras manifestações que, desde a década de 1980, provocavam discussões acerca da Previdência Social, até atingirem um 
estado de hegemonia, saindo do "âmbito técnico e acadêmico e ocupando posição central no debate político do país" (BARROS, 2007, p. 14).

\section{Considerações finais}

É preciso muito pouco para que sejamos persuadidos a aceitar a opinião enganosa de que o envelhecimento é igual em todo tempo e lugar e em todas as situações. Porém, não há uma homogeneidade no envelhecer. Ele está atrelado às relações de forças em cada formação social, em contextos específicos de cada momento histórico.

Dado seu caráter biológico (nascer, viver, envelhecer e morrer), há certa tendência em normatizá-lo, via ideologias hegemônicas, "tecnologias rejuvenescedoras", que, apoiadas pelas mídias, oferecem os mais variados kits, comprimidos e cirurgias que determinam o envelhecimento como uma busca constante pelo rejuvenescimento. Nesse movimento, cria-se um tipo de "idoso(a) universal", que "estigmatiza os que não se enquadram neste perfil, culpando-os(as) por seu declínio natural da velhice [...]" (SILVA, 2011, p. 41).

De acordo com Hall (2003a), precisamos compreender melhor as tensões e contradições geradas pelos compassos e pelas direções irregulares do desenvolvimento histórico. $\mathrm{O}$ impacto do aumento da expectativa de vida é irregular, e a própria irregularidade desse impacto pode ajudar a aprofundar e exacerbar os antagonismos contraditórios.
Tal impacto não é um fato "natural", é condicionado por fatores econômicos, políticos, sociais, demográficos, culturais, da "dialética das relações entre estrutura e superestrutura", produzindo, por conseguinte, efeitos distintos, que determinarão leis específicas e novas lutas hegemônicas. Isso não significa que modelos não possam ser criados e seguidos, entretanto, de acordo com Thompson, não se pode construir história sem modelo, mas não se pode se tornar escravo dos modelos, já que existe uma grande disputa entre modelo e realidade, e precisamos nos orientar pela realidade em primeiro plano. No caso do envelhecimento, a realidade não está dada, mas emaranhada numa complexidade sincrônica.

Tomar a análise, por exemplo, sobre o movimento de um grupo de pessoas aposentadas, de modo reducionista, somente levando em consideração aspectos de classe - no seu sentido rígido - ou de fatores econômicos, inviabiliza uma compreensão mais geral do fenômeno do envelhecimento.

É necessário, portanto, privilegiar, em uma análise, por exemplo, sobre o movimento dos aposentados, a dinamicidade do processo de formação da consciência de classe e as experiências surgidas nas "bordas" de uma história linear cronológica. Com base nas reflexões dos conceitos trabalhados neste artigo, observou-se que envelhecimento e seus conceitos análogos, como "terceira idade" e "aposentados", não podem ser definidos como homogêneos, lineares e, tão pouco, podem ser reduzidos a um "economismo" ou, ainda, vinculados a uma condição de 
classe social determinada. Envelhecer ou estar aposentado é diferente em várias partes do mundo, além de sofrer mudanças ao longo da história e do tempo.

Thompson demonstra as particularidades e sutilezas dos costumes dos povos durante a passagem do processo de industrialização na Inglaterra, fazendo-nos refletir sobre como o lugar das pessoas idosas foi gradativamente se alterando, conforme se alteravam também as concepções de tempo, trabalho e consciência de classe. Um conceito influencia o outro.

Apesar de Thompson e Gramsci não terem se dedicado ao estudo do envelhecimento, suas elucubrações podem ser utilizadas para pensar as dinâmicas física, biológica, política e cultural da vida humana, as possibilidades de articulações hegemônicas, por isso, sugerimos que novas análises sejam feitas em relação ao processo de envelhecimento a partir de seu lugar de enunciação, considerando o movimento da história.

\section{Aging in perspectives on time, experience and awareness class in Edward Palmer Thompson and Antônio Gramsci}

\section{Abstract}

The article moves on the issues of human aging from the perspective of the concepts of "time" and "class consciousness" in Edward Palmer Thompson and Antônio Gramsci, in dialogue with other authors. Based on narrative revision of literature, it was concluded that aging can not be defined as something homogeneous, linear or reduced to certain "economism". Through the peculiarities and nuances of the customs of the people during the process of industrialization in England in the eighteenth century and the movement of retirees in Brazil in 1990s, could be argued how the concept of aging and the place of older and retired people was gradually altered according to changes in conceptions of time, experience and class consciousness.

Keywords: Aging. Class consciousness. Experience. Time.

\section{Notas}

1 "Exemplos: em Madagáscar, o tempo podia ser medido pelo 'cozimento do arroz' ou pelo 'fritar de um gafanhoto'. Em Cross River, se dizia 'o homem morreu em menos tempo do que leva o milho para assar'. No Chile do século XVII o tempo era medido em 'Credos'. Na Birmânia, em tempos recentes, os monges levantavam ao amanhecer 'quando há bastante luz para ver as veias na mão"' (THOMPSON, 1998, p. 268).

2 Para Giddens, a modernidade se situa a partir do século XVII: “[...] modernidade refere-se a estilos, costume de vida ou organização social que emergiram na Europa a partir do século XVII" (1991, p. 11). Modernidade é entendida por ele como sinônimo de sociedade moderna ou industrial, com influências econômicas mais perceptíveis do que em outras formas de sociedade, a saber, o capitalismo; mas não só, também devido ao distanciamento do espaço e do tempo, padronizado pelo relógio mecânico, e à ruptura com o passado e a tradição, "enquanto modo de integrar a monitoração da ação com a organização tempo-espacial da comunidade" (GIDDENS, 1991, p. 44-45), ou seja, parafraseando Foucault (2001): "vigiar e punir".

\section{Referências}

ANDRADE, V. Lazer, controle e resistência: um olhar a partir da obra de Edward Palmer Thompson. In: ALVES JUNIOR, E. D. (Org.). Envelhecimento e vida saudável. Rio de Janeiro: Apicuri, 2009. p. 81-102.

BADARÓ MATTOS, M. E. P. Thompson e a tradição de crítica ativa do materialismo histórico. Rio de Janeiro: UFRJ, 2012. 
BARROS, M. Velhice ou terceira idade? 4. ed. São Paulo: FVG, 2007.

BEAUVOIR, S. A velhice. Rio de Janeiro: Nova Fronteira, 1991.

BOSI, E. O tempo vivo da memória: ensaios de psicologia social. 3. ed. São Paulo: Ateliê Editorial, 2003.

CÍCERO, M. T. Saber envelhecer. Porto Alegre: L\&PM, 2001.

FOUCAULT, M. Vigiar e punir: história da violência nas prisões. São Paulo: Vozes, 2001.

GRAMSCI, A. Caderno 12: apontamentos e notas dispersas para o grupo de ensaios sobre a história dos intelectuais. In:

Cadernos do Cárcere, v. 2. Rio de Janeiro: Civilização Brasileira, [1932] 2000. p. 13-53.

GIDDENS, A. As conseqüências da modernidade. São Paulo: Unesp, 1991.

HALL, S. A relevância de Gramsci para o estudo de raça e etnicidade. In: . $D a$

diáspora: identidades e mediações culturais. Belo Horizonte: UFMG, 2003a. p. 294-334.

. Stuart Hall por Stuart Hall. In:

Da diáspora: identidades e mediações culturais. Belo Horizonte: UFMG, 2003b. p. 404-433.

LACLAU, E. Depoimento [nov. 2013]. "La última entrevista de Ernesto Laclau con LA NACION". Entrevista concedida a Diego Sehinkman. La Nación, 13 abr. 2014.

MAGALHÃES, D. N. A invenção social da velhice. Rio de Janeiro: Papagaio, 1989.

MANNHEIM, K. Essays on the sociology of knowledge. Collected Works Volume Five. Edição de Paul Kecskemeti. London, 1998.

MÜLLER, R. G. A ideia de exterminismo em E. P. Thompson: realismo e contradição. In: MISSE, M.; WERNECK, A. (Org.). Conflitos de (grande) interesse: estudos sobre crimes, violências e outras disputas conflituosas. Rio de Janeiro: Garamond; Faperj, 2012. p. 305-336.
SEEGER, A. Povos indígenas no Brasil: sociedade e rituais. 2003. Disponível em: $<$ http://pib.socioambiental.org/pt/povo/kisedje/1226>. Acesso em: 10 jan. 2011.

SILVA, E. L. Velhices masculinas: um estudo sobre experiências do envelhecer. 2011. Trabalho de Conclusão de Curso (Graduação em Ciências Sociais) - Departamento de Sociologia e Ciência Política, Universidade Federal de Santa Catarina, Florianópolis, 2011.

THOMPSON, E. P. Costumes em comum: estudos sobre a cultura popular tradicional. São Paulo: Companhia das Letras, 1998.

. Notas sobre o exterminismo, o estágio final da civilização. In: THOMPSON, E. P. et al. Exterminismo e guerra fria. São Paulo: Brasiliense, 1985. p. 15-57.

VENDRAMINI, C. R. Experiência e coletividade em E. P. Thompson. In: MULLER, R. G.; DUARTE, A. Luiz. (Org.). E. P. Thompson: política e paixão. Chapecó: Argos, 2012. p. 127-147.

WALLERSTEIN, I. M. Impensar a ciência social. Aparecida: Ideias e Letras, 2006.

World-Systems Analysis: an introduction. Durham: Duke University Press, 2004.

WILLIAMS, R. et al. May day manifesto: 1968. Harmondsworth: Penguin Books, 1968. 